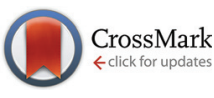

Cite this: Polym. Chem., 2017, 8, 366

Received 24th October 2016, Accepted 21st November 2016

DOI: $10.1039 /$ c6py01864e

www.rsc.org/polymers

\section{Metathesis polymerization of cystine-based macrocycles $\dagger$}

\author{
Felix N. Behrendt and Helmut Schlaad*
}

\begin{abstract}
Macrocycles based on L-cystine were synthesized by ring-closing metathesis (RCM) and subsequently polymerized by entropy-driven ring-opening metathesis polymerization (ED-ROMP). Monomer conversion reached $\sim 80 \%$ in equilibrium and the produced poly (ester-amine-disulfide-alkene)s exhibited apparent molar masses $\left(M_{\mathrm{w}}^{\mathrm{app}}\right)$ of up to $80 \mathrm{kDa}$ and dispersities $(\boldsymbol{\theta})$ of $\sim 2$. The polymers can be further functionalized with acid anhydrides and degraded by reductive cleavage of the main-chain disulfide.
\end{abstract}

Nature offers a large variety of platform chemicals, e.g., vegetable oils, amino acids, sugars, or terpenes, which can be used for the sustainable replacement of typical fossil fuel-derived chemicals and also for making new materials with advanced properties and functions. ${ }^{1-6}$ However, biological compounds usually carry multiple functional sites, resulting in the need for synthetic procedures with high selectivity and functional group tolerance and/or tedious protecting group chemistry. With the discovery of ruthenium-based metal alkylidene catalysts by Grubbs, ${ }^{7}$ the olefin metathesis reaction, including ring-opening metathesis polymerization (ROMP), ${ }^{8-10}$ meets the requirements for high selectivity and functional group tolerance. In particular, acyclic diene metathesis (ADMET) polymerization $^{11,12}$ has proven very useful for the polycondensation of bio-derived $\alpha, \omega$-unsaturated monomers (e.g., amino alcohols, amino acids, diketopiperazines, and fatty acid esters). ${ }^{13-16}$

Cysteine and its corresponding disulfide dimer, cystine, are multifunctional molecules that nature uses, among others, for the stabilization of proteins, e.g., insulin or keratins, and redox systems. ${ }^{17}$ Owing to its redox-active disulfide bridge, the incorporation of cystine into the backbone of a polymer facilitates a reductively triggered degradation. Polymers with disulfide links are also considered to be self-healing materials. ${ }^{18}$ Yet the only example of a cystine-based aliphatic polyester was

University of Potsdam, Institute of Chemistry, Karl-Liebknecht-Straße 24-25, 14476 Potsdam, Germany.E-mail:schlaad@uni-potsdam.de

$\dagger$ Electronic supplementary information (ESI) available: Experimental procedures, model reactions, ${ }^{1} \mathrm{H},{ }^{13} \mathrm{C},\left[{ }^{1} \mathrm{H},{ }^{1} \mathrm{H}\right]$ COSY NMR and ESI-ToF MS spectra, elemental analysis, SEC, SLS, and TGA/DSC data. See DOI: 10.1039/c6py01864e synthesized by melt polycondensation of an L-cystine ester derivative with ethylene glycols. ${ }^{19}$ This procedure, however, proceeds with a titanium-based catalyst at $120{ }^{\circ} \mathrm{C}$ in the bulk and further requires an exact stoichiometric match of the functional groups in order to reach high mass polymers. In contrast with this, metathesis polymerizations are usually conducted under milder conditions. However, reports of the incorporation of disulfides into polymers via metathesis polymerization are scarce. Attempts to homopolymerize a disulfide containing cyclooctene derivative by ROMP failed due to the negative neighboring group effect of the disulfide. ${ }^{20}$ Also, free sulfhydryl containing norbornene monomers failed, while the $S$-acetamidomethyl protected derivatives could be successfully polymerized by ROMP. ${ }^{10}$

Herein, we introduce L-cystine as a bio-sourced chemical to prepare a toolbox of monomers for metathesis polymerization (Scheme 1). The available $N$-Boc-protected derivative, $N, N^{\prime}$-di(tert-butyloxycarbonyl)-L-cystine $\mathbf{1}$, was reacted with either 4-bromobut-1-ene or 11-bromoundec-1-ene, using potassium carbonate as a base in $N, N$-dimethylformamide (DMF), to give the acyclic dialkenyl-( $N, N^{\prime}$-di-Boc)-L-cystines $2 \mathrm{a}$ (isolated yield: $90 \%$ ) and 2 b (61\%), respectively (see NMR spectra in the ESI $\dagger$ ).

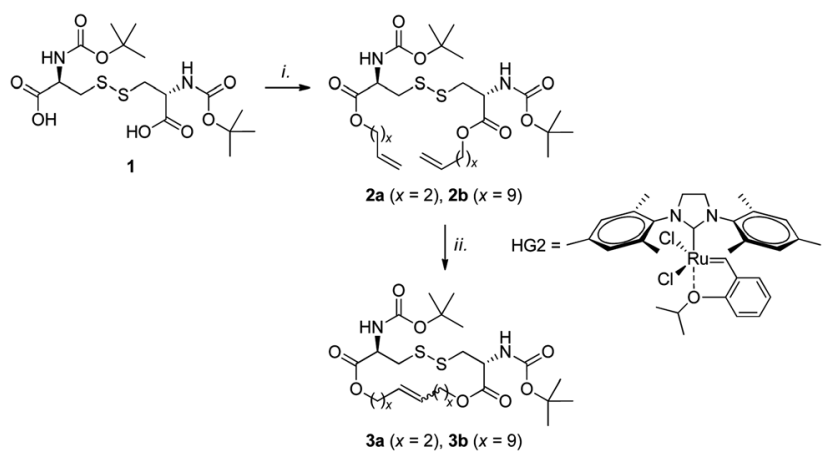

Scheme 1 Synthesis of L-cystine-based acyclic and macrocyclic monomers; (i) 4-bromobut-1-ene $(x=2)$ or 11-bromoundec-1-ene $(x=9)$ (3 equiv.), $\mathrm{K}_{2} \mathrm{CO}_{3}, \mathrm{DMF}, \mathrm{rt}, 4 \mathrm{~d}$; (ii) HG2, p-benzoquinone, $\mathrm{DCM}, 40^{\circ} \mathrm{C}, 6 \mathrm{~h}$. 


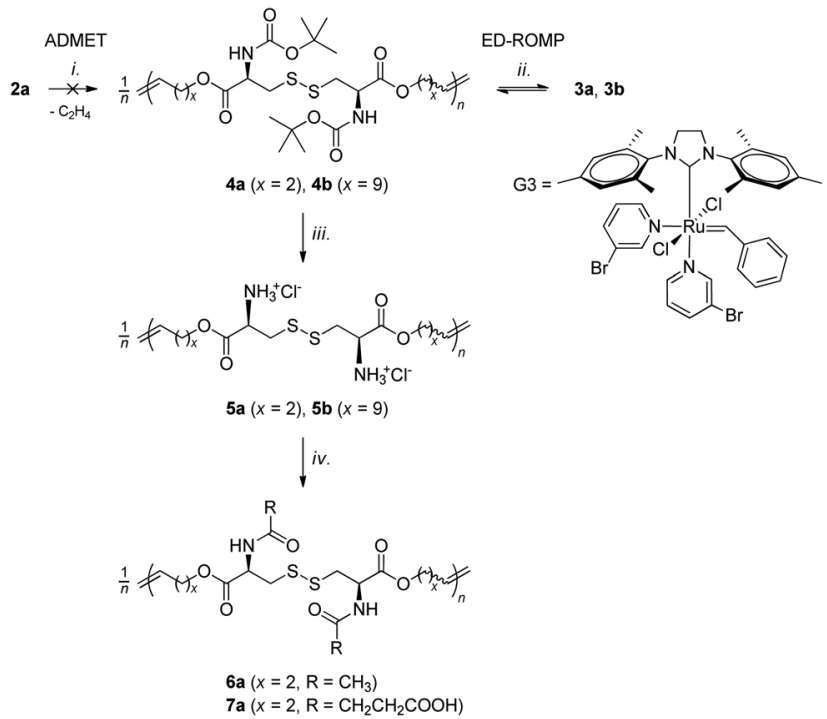

Scheme 2 Metathesis polymerization; (i) HG2, DCM, $40{ }^{\circ} \mathrm{C}, 6 \mathrm{~h}$; (ii) G3, $\mathrm{CHCl}_{3}, 40^{\circ} \mathrm{C}, 1 \mathrm{~h}$. Polymer deprotection; (iii) $1 \mathrm{M} \mathrm{HCl}$ in ethyl acetate, rt, $2 \mathrm{~d}$. Polymer functionalization; (iv) acetic or succinic anhydride, TEA, $\mathrm{DMF}, \mathrm{rt}, 5 \mathrm{~h}$.

We first attempted the ADMET polymerization of $\mathbf{2 a}$ (Scheme 2) in a $0.2 \mathrm{M}$ dichloromethane (DCM) solution, catalyzed by Hoveyda-Grubbs $2^{\text {nd }}$ generation catalyst (HG2) (catalyst loading: $\left.[\mathrm{HG} 2]_{0} /[2 \mathrm{a}]_{0}=0.05\right)$. Analysis of the crude polymerization mixture by ${ }^{1} \mathrm{H}$ NMR spectroscopy revealed a full conversion of the terminal vinyl double bonds after $42 \mathrm{~h}$. However, size exclusion chromatography (SEC) detected only low molar mass products, which was suspected to contain macrocycles, but virtually no polymer. Another attempt to polymerize $2 \mathrm{a}$ at $1.2 \mathrm{M}$ in chloroform led to just $60 \%$ double bond conversion and production of oligomers (see SEC trace in the $\mathrm{ESI}_{\dagger}^{\dagger}$ ).

Macrocycle 3a was synthesized by a ring-closing metathesis $(\mathrm{RCM})$ of $2 \mathrm{a}$ in a $0.01 \mathrm{M}$ DCM solution using $[\mathrm{HG} 2]_{0} /[2 \mathrm{a}]_{0}=$ 0.01 ; para-benzoquinone was added to suppress the isomerization of double bonds. ${ }^{21,22}$ The isolated purified 16-membered macrocycle 3a (yield: 85\%) formed needle-like crystals (m.p. 176-178 ${ }^{\circ} \mathrm{C}$ ). The ring structure was confirmed by ${ }^{1} \mathrm{H}$, ${ }^{13} \mathrm{C}$, and $2 \mathrm{D}\left[{ }^{1} \mathrm{H},{ }^{1} \mathrm{H}\right]$ COSY NMR spectroscopy as well as by electrospray ionization time-of-flight (ESI-ToF) mass spectrometry $\left(\mathrm{ESI}^{\dagger}\right)$. The cis/trans ratio of the internal double bond was found to be $0.15-0.2$ by ${ }^{1} \mathrm{H}$ NMR spectroscopy. Interestingly, the ${ }^{1} \mathrm{H}$ NMR spectrum of 3 a revealed a geminal coupling of the methylene group adjacent to the ester group $\left(-\mathrm{C}(\mathrm{O}) \mathrm{C}_{2}-\right.$, signal b in Fig. 1), which was attributed to the stereocenter of the amino acid and the hindered rotation within the cycle.

Similarly, the 30-membered macrocycle $\mathbf{3 b}$ was obtained from 2 b with a yield of $31 \%$ (colorless solid, m.p. $83-85{ }^{\circ} \mathrm{C},{ }^{1} \mathrm{H}$ NMR and ESI-ToF mass spectra in the ESI $\dagger$ ).

We then applied entropy-driven ring-opening metathesis polymerization (ED-ROMP) to macrocycles $\mathbf{3 a}$ and $\mathbf{3 b}$ (Scheme 2). In contrast with conventional ROMP, which is usually performed with strained rings like norbornenes, ${ }^{8}$

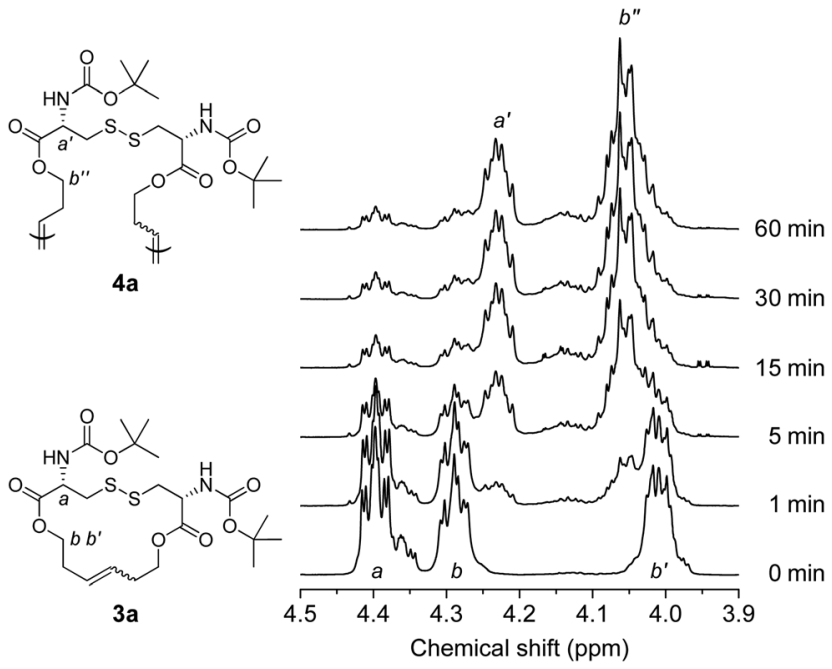

Fig. $1{ }^{1} \mathrm{H}$ NMR spectra (600 MHz, DMSO- $\mathrm{d}_{6}, 3.9-4.5 \mathrm{ppm}$ range) of 3a $(0 \mathrm{~min})$ and crude polymerization mixtures $3 a / 4 a$ at different reaction times $(1,5,15,30$, and $60 \mathrm{~min})$.

ED-ROMP does not follow a controlled or "living" polymerization pathway. ${ }^{23}$ Macrocycles do not exhibit any ring strain and hence there is no enthalpic contribution to drive the equilibrium reaction towards the formation of the polymer. ED-ROMP is therefore conducted at high monomer concentrations in order to entropically favor the polymerization reaction. It has been shown that ED-ROMP often outperforms standard ADMET polymerizations with respect to molar mass as well as reaction time. Macrocyclic olefins that have been successfully polymerized by ED-ROMP include unsaturated crown ether analogs (polyether with number-average molar mass, $M_{\mathrm{n}}=66 \mathrm{kDa}$, and dispersity, $\left.D=2\right),{ }^{24}$ sequence-encoded lactides $\left(M_{\mathrm{n}}=20-60 \mathrm{kDa}, Ð=1.3-1.5\right),{ }^{25}$ oligoamides $\left(M_{\mathrm{n}}=\right.$ $10-30 \mathrm{kDa}){ }^{26}$ as well as naturally derived bile acid derivatives $\left(M_{\mathrm{n}}>100 \mathrm{kDa}\right)^{27}$ and glycolipid $\left(M_{\mathrm{n}}=75-190 \mathrm{kDa}\right){ }^{28}$

Polymerization of $\mathbf{3 a}$ was performed using the Grubbs $3^{\text {rd }}$ generation catalyst $(\mathrm{G} 3)\left([\mathrm{G} 3]_{0} /[3 \mathrm{a}]_{0}=0.01\right)$ at $30 \mathrm{wt} \%$ in chloroform $\left([3 \mathrm{a}]_{0}=1.24 \mathrm{~m}\right)$ at $40{ }^{\circ} \mathrm{C}$. (Note: G3 exhibits a higher initiation rate $^{29}$ than HG2, which eventually leads to higher monomer conversion and higher molar mass polymer (see ESI $\dagger$ ).) Monomer conversion could be monitored using ${ }^{1} \mathrm{H}$ NMR analysis (Fig. 1) since the polymer does not show geminal coupling, unlike the monomer. The first-order timeconversion plot (Fig. 2a) is non-linear, as expected, with a maximum monomer conversion of $80 \%$ at the thermodynamic equilibrium $\left([3 \mathrm{a}]_{\mathrm{eq}}=0.025 \mathrm{M}\right.$ at $\left.40{ }^{\circ} \mathrm{C}\right)$, which is reached after $\sim 30$ minutes. The weight-average molar mass $\left(M_{\mathrm{w}}^{\mathrm{app}}\right.$, by SEC with polystyrene calibration) of the polymer increased linearly with conversion (Fig. 2b), and the final polymer 4a exhibited an apparent $M_{\mathrm{w}}^{\mathrm{app}}=58.7 \mathrm{kDa}(\nexists=2.2)$ (SEC-RI traces in Fig. 2c); absolute $M_{\mathrm{w}}=(23 \pm 4) \mathrm{kDa}$ (static light scattering, SLS) (ESI $\dagger$ ). The large difference between the $M_{\mathrm{w}}^{\text {app }}$ and $M_{\mathrm{w}}$ values might indicate that the polymer chains adopt an extended conformation rather than a random coil conformation. Polymer 4a is thermally stable up to $T_{\mathrm{d}} \sim 160{ }^{\circ} \mathrm{C}$ (thermogravimetric 

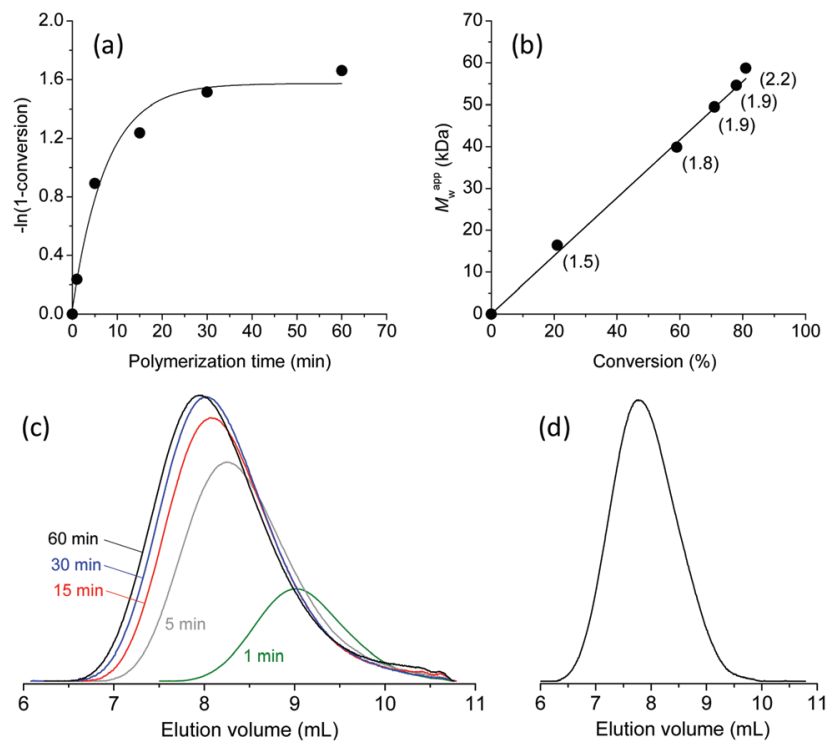

Fig. 2 ED-ROMP of macrocycle 3a; (a) first-order time-conversion plot (conversion determined by ${ }^{1} \mathrm{H}$ NMR spectroscopy), (b) evolution of apparent weight-average molar mass $M_{\mathrm{w}}^{\mathrm{app}}$ of polymer 4a with monomer conversion (values in parentheses are dispersity indexes, SEC), and (c) SEC-RI traces (eluent: THF) of purified polymer 4a obtained at different reaction times $(1,5,15,30$, and $60 \mathrm{~min}$ ) (areas under $\mathrm{RI}$ signals are normalized to monomer conversion). (d) SEC-RI trace of polymer $\mathbf{4 b}$.

analysis, TGA) and exhibits a glass transition temperature $\left(T_{\mathrm{g}}\right)$ of $41{ }^{\circ} \mathrm{C}$ (differential scanning calorimetry, DSC) (ESI $\dagger$ ). The macrocycle $\mathbf{3 b}$ was also successfully polymerized with the G3 catalyst (the same reaction conditions as those for $\mathbf{3 a}$ ) to yield polymer 4b with $M_{\mathrm{w}}^{\mathrm{app}}=80 \mathrm{kDa}(\nexists=1.7)$ (SEC, Fig. 2d) within 30 minutes; $T_{\mathrm{d}} \sim 170^{\circ} \mathrm{C}, T_{\mathrm{g}}=2^{\circ} \mathrm{C}$.

The kinetic study suggests that the disulfide bond seems not to have a negative neighboring effect during metathesis polymerization, as was earlier observed for other disulfidecontaining monomers (see above), which might be attributed to the large distance between the double bond (catalyst site) and disulfide. Furthermore, the disulfide unit might be sterically shielded by the vicinal Boc-protecting group to prevent interactions with the catalyst.

Deprotection of the polymers $\mathbf{4 a}$ and $\mathbf{4 b}$ was achieved with $\mathrm{HCl}$ in ethyl acetate at room temperature. Interestingly, the first sample formed an organogel in the course of the reaction (even at a polymer concentration as low as 0.5 wt \%). Nevertheless, removal of the Boc-protecting groups was quantitative, as confirmed by ${ }^{1} \mathrm{H}$ NMR analysis (ESI $\dagger$ ), and yielded the water-soluble (or dispersible) polymers 5a $\left(M_{\mathrm{w}}=(15 \pm 6)\right.$ $\mathrm{kDa}, \mathrm{SLS})$ and $\mathbf{5 b}$ with the primary ammonium chloride side groups (Scheme 2).

The pendant amino groups can be functionalized with, for instance, acid anhydrides. Exemplarily, 4a was first deprotected with $\mathrm{HCl} /$ ethyl acetate $(\rightarrow \mathbf{5 a})$ and immediately treated with triethylamine (TEA) and either acetic anhydride $(\rightarrow \mathbf{6 a})$ or succinic anhydride $(\rightarrow 7 \mathbf{a})$ in a 3 -fold excess. The expected chemical structures of the functionalized polymers (Scheme 2) could be confirmed by ${ }^{1} \mathrm{H}$ NMR spectroscopy
(ESI $\dagger$ ). However, the samples could not be analyzed by SEC due to their poor solubility in THF (eluent).

Polymers 4-7 should undergo degradation either by hydrolysis of the main-chain ester or by reduction (oxidation) of the disulfide. Exemplarily, the reductive degradation of 4a was achieved in less than 30 minutes (followed by SEC) with a 10-fold excess of dithioerythritol (DTE) and catalytic amounts of TEA. ${ }^{1} \mathrm{H}$ NMR analysis revealed that the polymer was finally broken down to the single monomer unit, by comparison with the reduction product of macrocycle $3 \mathbf{a}(\mathrm{ESI} \dagger)$.

In summary, we described a new route to hetero-multifunctional polyesters by metathesis polymerization of bio-sourced cystine-based macrocycles. The G3-catalyzed ED-ROMP afforded high molar mass polymers of up to $80 \mathrm{kDa}$ $\left(M_{\mathrm{w}}^{\mathrm{app}}, \mathrm{SEC}\right)$ and a dispersity of $\sim 2$ within a reaction time of $30 \mathrm{~min}$, outperforming the melt polycondensation procedure of L-cystine diesters. ${ }^{19}$ Importantly, the metathesis reaction was not disturbed by the presence of the disulfide units. The polymers can be further functionalized with acid anhydrides and degraded by reductive cleavage of the disulfide with DTE/TEA.

Present work is devoted to further extension of the toolbox of cystine-based monomers for olefin and disulfide metathesis polymerization. The multifunctionality of the polymers shall be used to prepare (keratin-mimicking) materials with advanced properties, for instance, stimuli-responsiveness or self-healing ability, as well as hydrogels and composite materials.

We thank Sascha Prentzel, Angela Krtitschka, Sylvia Fürstenberg, Ines Starke, Yasemin Mai-Linde, Ahed Abouserie, Dirk Schanzenbach, Sebastian Noack, and Anna Bogomolova for their help and technical assistance. Financial support was given by the University of Potsdam.

\section{Notes and references}

1 K. Yao and C. Tang, Macromolecules, 2013, 46, 16891712.

2 A. Gandini and T. M. Lacerda, Prog. Polym. Sci., 2015, 48, 1-39.

3 A. Gandini, T. M. Lacerda, A. J. F. Carvalho and E. Trovatti, Chem. Rev., 2016, 116, 1637-1669.

4 J. A. Galbis, M. D. G. García-Martín, M. V. de Paz and E. Galbis, Chem. Rev., 2016, 116, 1600-1636.

5 N. Gangloff, J. Ulbricht, T. Lorson, H. Schlaad and R. Luxenhofer, Chem. Rev., 2016, 116, 1753-1802.

6 J. Zhao and H. Schlaad, Adv. Polym. Sci., 2013, 253, 151190.

7 S. T. Nguyen, L. K. Johnson, R. H. Grubbs and J. W. Ziller, J. Am. Chem. Soc., 1992, 114, 3974-3975.

8 C. W. Bielawski and R. H. Grubbs, Prog. Polym. Sci., 2007, 32, 1-29.

9 A. A. Nagarkar and A. F. M. Kilbinger, Nat. Chem., 2015, 7, 718-723.

10 J. K. Kammeyer, A. P. Blum, L. Adamiak, M. E. Hahn and N. C. Gianneschi, Polym. Chem., 2013, 4, 3929-3933. 
11 T. W. Baughman and K. B. Wagener, Adv. Polym. Sci., 2005, 176, 1-42.

12 P. Atallah, K. B. Wagener and M. D. Schulz, Macromolecules, 2013, 46, 4735-4741.

13 K. Terada, E. B. Berda, K. B. Wagener, F. Sanda and T. Masuda, Macromolecules, 2008, 41, 6041-6046.

14 O. Türünc and M. A. R. Meier, Green Chem., 2011, 13, 314320.

15 T. E. Hopkins, J. H. Pawlow, D. L. Koren, K. S. Deters, S. M. Solivan, J. A. Davis, F. J. Gómez and K. B. Wagener, Macromolecules, 2001, 34, 7920-7922.

16 F. N. Führer and H. Schlaad, Macromol. Chem. Phys., 2014, 215, 1521-3935.

17 J. M. Berg, J. L. Tymoczko and L. Stryer, Biochemie, Springer-Verlag, Berlin, Heidelberg, 2013.

18 J. Canadell, H. Goossens and B. Klumperman, Macromolecules, 2011, 44, 2536-2541.

19 S. Anantharaj and M. Jayakannan, J. Polym. Sci., Part A: Polym. Chem., 2016, 54, 2864-2875.
20 C. C. Chang and T. Emrick, Macromolecules, 2014, 47, 1344-1350.

21 S. H. Hong, D. P. Sanders, C. W. Lee and R. H. Grubbs, J. Am. Chem. Soc., 2005, 127, 17160-17161.

22 P. A. Fokou and M. A. R. Meier, Macromol. Rapid Commun., 2010, 31, 368-373.

23 Z. Xue and M. F. Mayer, Soft Matter, 2009, 5, 4600-4611.

24 M. J. Marsella, H. D. Maynard and R. H. Grubbs, Angew. Chem., Int. Ed. Engl., 1997, 36, 1101-1103.

25 R. M. Weiss, A. L. Short and T. Y. Meyer, ACS Macro Lett., 2015, 4, 1039-1043.

26 C. Y. Tastard, P. Hodge, A. Ben-Haida and M. Dobinson, React. Funct. Polym., 2006, 66, 93-107.

27 J. E. Gautrot and X. X. Zhu, Macromolecules, 2009, 42, 7324-7331.

28 Y. Peng, J. Decatur, M. A. R. Meier and R. A. Gross, Macromolecules, 2013, 46, 3293-3300.

29 J. A. Love, J. P. Morgan, T. M. Trnka and R. H. Grubbs, Angew. Chem., Int. Ed., 2002, 41, 4035-4037. 